\title{
Synthesis, Crystal Structures, and Spectroscopic and Thermal Properties of New Cobalt Thiocyanato Coordination Compounds Based on 3-Methylpyridine as a Neutral Coligand
}

\author{
Jan Boeckmann, Björn Reimer, and Christian Näther \\ Institut für Anorganische Chemie, Christian-Albrechts-Universität zu Kiel, Max-Eyth-Straße 2, \\ 24118 Kiel, Germany \\ Reprint requests to Prof. Dr. Christian Näther. Fax: +49-431-8801520. \\ E-mail: cnaether@ac.uni-kiel.de
}

Z. Naturforsch. 2011, 66b, 819-827; received June 15, 2011

\begin{abstract}
Reaction of cobalt(II) thiocyanate with 3-methylpyridine in water leads to the formation of the new ligand-rich cobalt(II) thiocyanato coordination compounds [bis(thiocyanato- $N$ )-tetrakis(3-methylpyridine- $N)$ cobalt(II)] (1) and [bis(thiocyanato- $N$ )-bis(3-methylpyridine- $N$ )-diaqua-cobalt(II)] (2). The crystal structures of $\mathbf{1}$ and $\mathbf{2}$ consist of discrete complexes in which the cobalt(II) cations are coordinated by two terminally $N$-bonded thiocyanato anions and four or two terminally bonded coligands, respectively, in a slightly distorted octahedral geometry. Investigations on the thermal degradation behavior of $\mathbf{1}$ and $\mathbf{2}$ using simultaneous differential thermoanalysis and thermogravimetry as well as $\mathrm{X}$-ray powder diffraction and IR spectroscopy have proven that on heating a stepwise decomposition takes place, which leads to the formation of the new phase-pure ligand-deficient intermediate [bis(thiocyanato- $N$ )-bis(3-methylpyridine- $N$ )cobalt(II)] (3). The crystal structure of $\mathbf{3}$ also consists of discrete complexes, but the cobalt(II) cations are only tetrahedrally coordinated by two terminally $N$-bonded thiocyanato anions and two terminally bonded coligands. The structures and the thermal properties are discussed and compared with that of related transition metal thiocyanato coordination compounds.
\end{abstract}

Key words: Coordination Chemistry, Cobalt(II) Thiocyanate, Crystal Structures, Thermochemistry

\section{Introduction}

In the last decade, the development of strategies for the rational design of low-dimensional solids which show slow relaxation of the magnetization and a hysteresis of molecular origin, so called single molecule magnets (SMMs) and single chain magnets (SCMs), have gained increasing interest due to their high potential for future applications as storage materials or in molecular electronics [1-8]. Whereas the SMMs have been well investigated since the beginning 1990s, the first experimental evidence for a SCM was reported in 2001 by Caneschi et al. [9], almost four decades after the theoretical prediction of Glauber for ferromagnetically coupled Ising spin chains [10]. Since that time, enormous efforts have been focused on the synthesis of one-dimensional (1D) structures, but up today there are just a few established examples [1125]. Therefore, a rational route to $1 \mathrm{D}$ materials which might show SCM behavior would be highly desirable. In this context, we reported on the directed syn- thesis of $1 \mathrm{D}$ and $2 \mathrm{D}$ cobalt(II) thiocyanato and selenocyanato coordination polymers [26-32]. For the preparation of chains, discrete complexes based on monodentate coligands and terminally $N$-bonded anions as ligand-rich precursor compounds (ligand-rich $=$ rich on neutral coligands) must be thermally decomposed. In this reaction the $1: 4(1: 4=$ ratio metal salt : neutral coligand) complexes transform selectively into ligand-deficient (ligand-deficient = lacking neutral coligands) 1D cobalt(II) thiocyanato and selenocyanato coordination polymers in which the formerly terminally bonded anions bridge the magnetically active metal centers into chains. Interestingly, for the thio- and selenocyanato compounds with pyridine as a coligand, single-chain magnetic behavior was observed for the first time in this class of compounds (Fig 1) [26, 27].

To further investigate if thermal decomposition reactions are a general, alternative synthetic strategy for the selective formation of $1 \mathrm{D}$ coordination compounds, we investigated analogous compounds based on the 


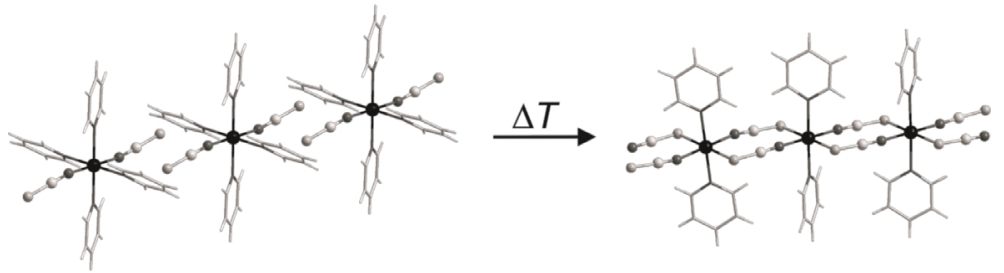

Fig. 1. Structural transformation of the discrete $1: 4$ complex $\left[\mathrm{Co}(\mathrm{NCS})_{2}\right.$ (pyridine $)_{4}$ ] with terminally bonded anions into the 1D ligand-deficient intermediate $\left.\left[\mathrm{Co}(\mathrm{NCS})_{2} \text { (pyridine }\right)_{2}\right]_{n}$ with $\mu-1,3$ bridging anions. monodentate coligand 3-methylpyridine. In this context the question arises if in the course of the thermal degradation reaction of the precursor any liganddeficient intermediates can be found, in which the octahedral coordination geometry of the cobalt(II) cations remains intact and therefore forces the formation of 1D compounds. This is highly likely because a corresponding 1:2 1D compound based on cadmium(II) thiocyanate is already known in the literature [33], and we have found that ligand-rich compounds with cadmium thio- or selenocyanate show a similar thermal reactivity. Their ligand-deficient intermediates are frequently isotypic to their paramagnetic counterparts [34-37].

\section{Results and Discussion}

\section{Synthetic investigations}

In order to obtain a ligand-rich $1: 4$ precursor complex, different molar ratios of cobalt(II) thiocyanate and 3-methylpyridine were reacted in water, and the resulting precipitates were investigated by XRPD measurements. These investigations have clearly proven that always one crystalline phase is found from any

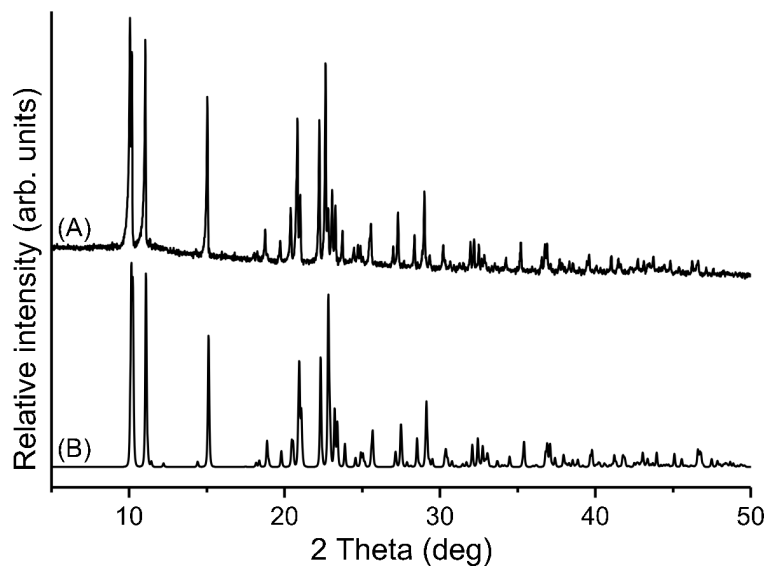

Fig. 2. Experimental powder pattern (A) together with the powder pattern calculated from single-crystal data of compound 1 (B). ratio in the range from $1: 10$ to $1: 1$. To determine the stoichiometry of this compound, elemental analysis of the crystalline powder 1 was performed, yielding a composition of $\left.\left[\mathrm{Co}(\mathrm{NCS})_{2} \text { (3-methylpyridine }\right)_{4}\right]$ and confirming the formation of a ligand-rich 1:4 compound. Finally, single crystals were grown, and the structure of the ligand-rich phase 1 was determined by $\mathrm{X}$-ray diffraction (see below). Comparison of the experimental and calculated XRPD patterns proves that compound 1 was formed phase-pure (Fig. 2).

\section{Crystal structure of the ligand-rich precursor 1}

The $1: 4$ compound $\left[\mathrm{Co}(\mathrm{NCS})_{2}(3\right.$-methylpyridine $)_{4}$ (1) crystallizes in the centrosymmetric orthorhombic space group Pbcn with four formula units in the unit cell. The cobalt(II) cations are located on a center of inversion and are coordinated by six nitrogen atoms of two terminally $\mathrm{N}$-bonded thiocyanato anions and four 3-methylpyridine coligands, all of them

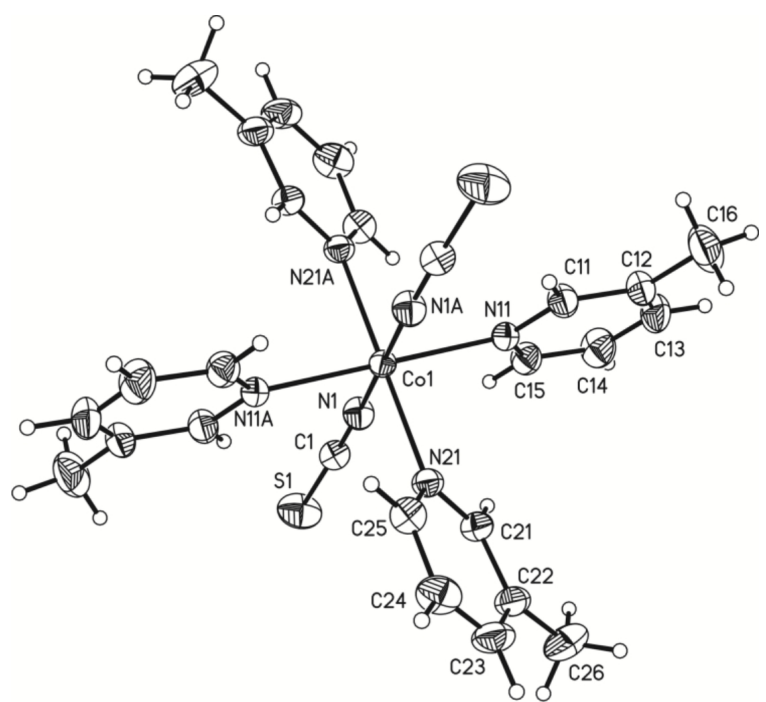

Fig. 3. Crystal structure of compound $\mathbf{1}$ with labeling and displacement ellipsoids drawn at the $50 \%$ probability level. Symmetry transformation used to generate equivalent atoms: A: $-x+1,-y+1,-z+1$. For clarity only one orientation of the disordered methyl $\mathrm{H}$ atoms of atom $\mathrm{C} 16$ is shown. 
Table 1. Selected bond lengths $(\AA)$ and angles (deg) for $\mathbf{1}$. Symmetry code: A: $-x+1,-y+1,-z+1$.

\begin{tabular}{llll}
\hline $\operatorname{Co}(1)-\mathrm{N}(1)$ & $2.0848(17)$ & $\mathrm{N}(1)-\mathrm{Co}(1)-\mathrm{N}(11 \mathrm{~A})$ & $91.42(6)$ \\
$\mathrm{Co}(1)-\mathrm{N}(11)$ & $2.2473(14)$ & $\mathrm{N}(1)-\mathrm{Co}(1)-\mathrm{N}(21)$ & $89.44(7)$ \\
$\mathrm{Co}(1)-\mathrm{N}(21)$ & $2.1860(16)$ & $\mathrm{N}(1)-\mathrm{Co}(1)-\mathrm{N}(21 \mathrm{~A})$ & $90.56(7)$ \\
$\mathrm{N}(1)-\mathrm{Co}(1)-\mathrm{N}(1 \mathrm{~A})$ & 180 & $\mathrm{~N}(11)-\mathrm{Co}(1)-\mathrm{N}(21 \mathrm{~A})$ & $91.18(5)$ \\
$\mathrm{N}(1)-\mathrm{Co}(1)-\mathrm{N}(11)$ & $88.58(6)$ & $\mathrm{N}(11)-\mathrm{Co}(1)-\mathrm{N}(21)$ & $88.82(5)$ \\
\hline
\end{tabular}

located in general positions, within a slightly distorted octahedral coordination geometry (Fig. 3). The $\mathrm{Co}^{\mathrm{II}}-\mathrm{N}$ distances lie between 2.0848(18) and 2.2477(15) $\AA$, while the angles around the cobalt(II) cations are between $88.58(6)$ and $180.0^{\circ}$ (Table 1 ).

\section{Thermoanalytical investigations of 1}

On heating compound $\mathbf{1}$ in a thermobalance to $450{ }^{\circ} \mathrm{C}$, a stepwise decomposition is observed. The DTG curve shows that the first mass step is well resolved and accompanied by an endothermic event in the DTA curve at $125^{\circ} \mathrm{C}$. The second mass step is not well resolved, but also accompanied by an endothermic event in the DTA curve at $161^{\circ} \mathrm{C}$ (Fig. 4). The experimental mass loss in the first step of $33.3 \%$ is in good agreement with that calculated for the removal of two molecules of 3-methylpyridine $\left(\Delta m_{\text {calcd. }}=-34.0 \%\right)$

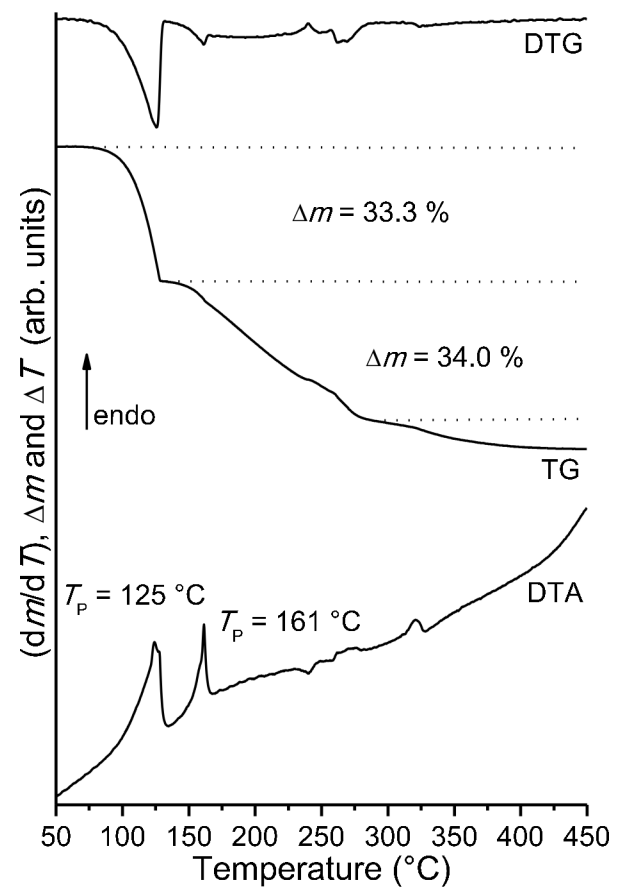

Fig. 4. DTG, TG and DTA curves for compound 1. Heating rate $=1{ }^{\circ} \mathrm{C} \min ^{-1}$; given are the mass changes $(\%)$ and the peak temperatures $T_{\mathrm{P}}\left({ }^{\circ} \mathrm{C}\right)$.
(Fig. 4). Thus, it can be assumed that in the first step a ligand-deficient $1: 2$ compound of composition $\left.\left[\mathrm{Co}(\mathrm{NCS})_{2} \text { (3-methylpyridine }\right)_{2}\right]$ is formed, and that in the second mass step the remaining 3-methylpyridine coligands are removed to give $\mathrm{Co}(\mathrm{NCS})_{2}$ which decomposes on further heating (Fig. 4).

In order to verify the nature of the intermediate formed, additional TG measurements were performed and stopped after the first mass step. Elemental analysis data of the residue obtained support that a liganddeficient $1: 2$ compound of composition $\left[\mathrm{Co}(\mathrm{NCS})_{2}(3-\right.$ methylpyridine $)_{2}$ ] is formed. Additional XRPD investigations of the residue have shown that it is not isotypic to the literature-known compound $\left[\mathrm{Cd}(\mathrm{NCS})_{2}(3-\right.$ methylpyridine $\left.)_{2}\right]_{n}$ (Fig. 5), as it was found for several other compounds based on $\mathrm{Co}(\mathrm{NCS})_{2}$ or $\mathrm{Co}(\mathrm{NCSe})_{2}$ and the monodentate coligand pyridine [26, 27,37].

To determine the coordination mode of the thiocyanato anions, all compounds were additionally investigated by IR spectroscopy (Fig. 6, left and middle). In compounds with terminally $N$-bonded thiocyanato anions the asymmetric $v_{\text {as }}(\mathrm{CN})$ band is expected at about $2050 \mathrm{~cm}^{-1}$, whereas for $\mu-1,3-N, S$ bridging anions $\nu_{\mathrm{as}}(\mathrm{CN})$ values of about $2100 \mathrm{~cm}^{-1}$ are expected [38]. Surprisingly, for the ligand-rich precursor 1 (Fig. 6 left) and the ligand-deficient intermediate 3 (Fig. 6, middle) values for $v_{\mathrm{as}}(\mathrm{CN})$ are found, which are characteristic for terminally bonded thiocyanato anions. Unfortunately, single crystals could not be prepared from solutions, but recrystallization of the residue obtained in the thermal decomposition

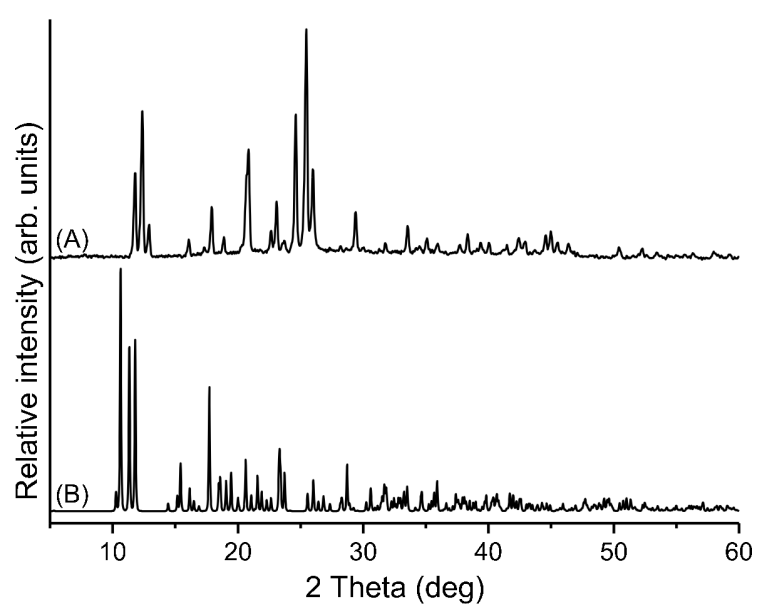

Fig. 5. Experimental powder pattern of the residue obtained in the thermal decomposition reaction of $\mathbf{1}$ (A) together with a calculated powder pattern from single-crystal data of compound $\left[\mathrm{Cd}(\mathrm{NCS})_{2}(3-\text { picoline })_{2}\right]_{n}(\mathrm{~B})$. 

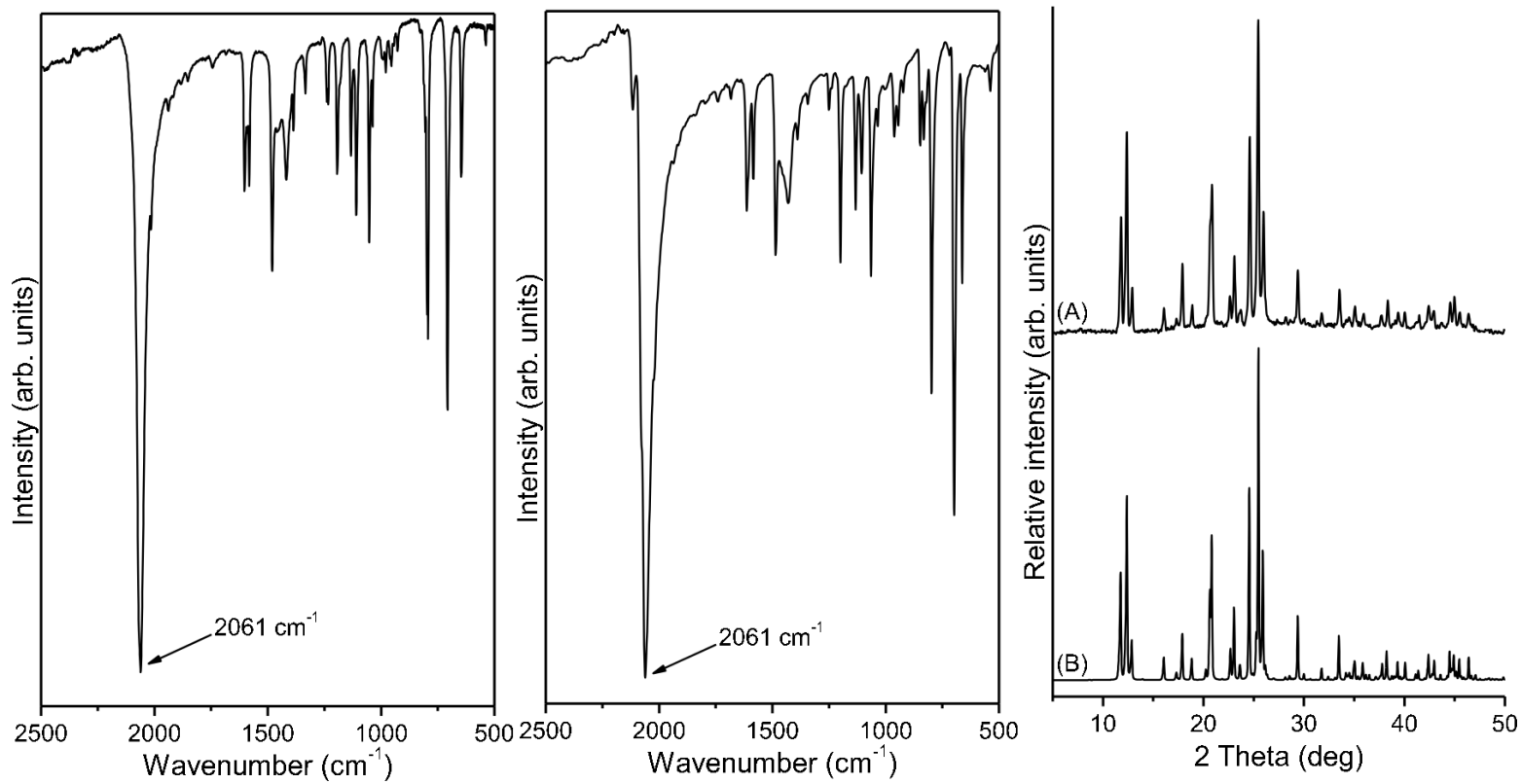

Fig. 6. Infrared spectra of compounds $\mathbf{1}$ (left) and $\mathbf{3}$ (middle) and the experimental powder pattern of the residue obtained in the thermal decomposition reaction of $\mathbf{1}(\mathrm{A})$, together with a powder pattern calculated from single-crystal data of compound $\mathbf{3}$ (B) (right).

reaction from acetonitrile resulted in the formation of crystals that were suitable for single-crystal structure analysis (see below). Comparison of the experimental XRPD pattern of the residue with that calculated for compound $\mathbf{3}$ clearly proves that $\mathbf{3}$ was formed phasepure after the first mass step in the thermal decomposition reaction (Fig. 6, right).

\section{Crystal structure of the ligand-deficient intermediate 3}

The $1: 2$ compound $\left[\mathrm{Co}(\mathrm{NCS})_{2}\right.$ (3-methylpyridine $)_{2}$ ] (3) crystallizes in the centrosymmetric orthorhombic space group Pnma with four formula units in the unit cell. The cobalt(II) cations are located on a mirror plane and are coordinated by four nitrogen atoms of two terminally $N$-bonded thiocyanato anions, also situated on a mirror plane, and two symmetry-related 3-methylpyridine coligands in a slightly distorted tetrahedral coordination geometry (Fig. 7). The $\mathrm{Co}^{\mathrm{II}}-\mathrm{N}$ distances range be-

Table 2. Selected bond lengths $(\AA)$ and angles (deg) for $\mathbf{3}$. Symmetry code: A: $x,-y+1 / 2, z$.

\begin{tabular}{llll}
\hline $\operatorname{Co}(1)-\mathrm{N}(1)$ & $1.933(3)$ & $\mathrm{N}(1)-\mathrm{Co}(1)-\mathrm{N}(2)$ & $119.50(16)$ \\
$\operatorname{Co}(1)-\mathrm{N}(2)$ & $1.937(3)$ & $\mathrm{N}(11)-\mathrm{Co}(1)-\mathrm{N}(11 \mathrm{~A})$ & $107.94(11)$ \\
$\operatorname{Co}(1)-\mathrm{N}(11)$ & $2.0214(19)$ & $\mathrm{N}(1)-\mathrm{Co}(1)-\mathrm{N}(11)$ & $107.83(8)$ \\
& & $\mathrm{N}(2)-\mathrm{Co}(1)-\mathrm{N}(11)$ & $106.63(8)$ \\
\hline
\end{tabular}

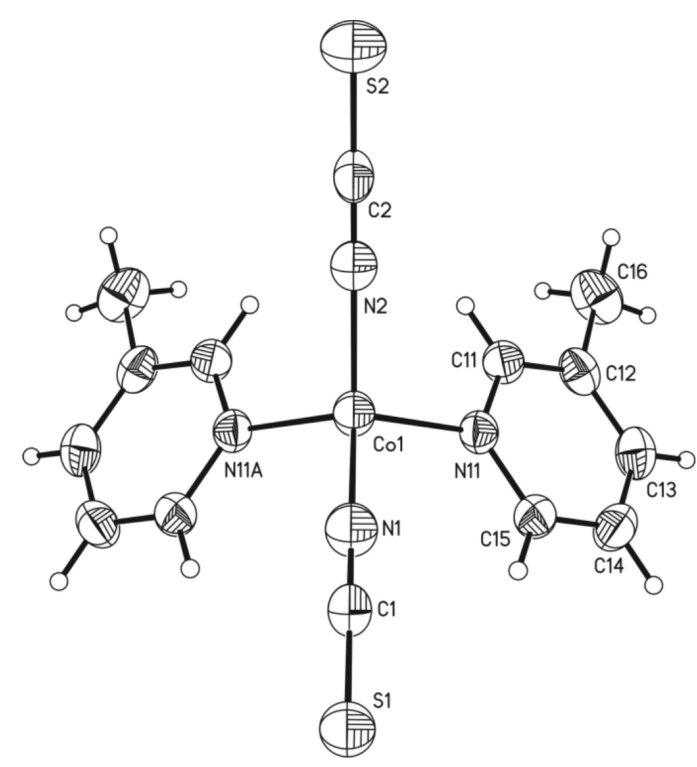

Fig. 7. Crystal structure of compound 3 with the atom labeling and with the displacement ellipsoids drawn at the $30 \%$ probability level. Symmetry transformation used to generate equivalent atoms: A: $x,-y+1 / 2, z$.

tween 1.933(3) and 2.0214(19) $\AA$, while the angles around the cobalt(II) cations are between 106.63(8) and $119.50(16)^{\circ}$ (Table 2). 


\section{Targeted variation of the ligand-rich precursor 1}

If the ligand-rich precursor complex $\left[\mathrm{Co}(\mathrm{NCS})_{2}(3-\right.$ methylpyridine $)_{4}$ ] (1) is thermally degraded, a transformation of the octahedral into a tetrahedral coordination geometry is found, leading to a discrete complex in which the thiocyanato anions are still terminally $N$ bonded, and therefore no magnetic exchange interactions can be expected. This is surprising because when investigating several other pyridine derivatives we always observed that the octahedral coordination is retained on thermal decomposition leading to the formation of 1D structures. In order to check if a different reactivity is observed if the precursor is modified, we tried to synthesize a new ligand-rich precursor with two different kinds of coligands, of which one is more volatile, like $e . g$. water, and thus is emitted in the first step on thermal decomposition. Therefore, different molar ratios of the starting materials were reacted in water, and the resulting precipitates were investigated by XRPD. The results of these experiments have proven that besides compound 1 another crystalline phase can be found if at least a twofold excess of cobalt(II) thiocyanate is used. The results of a structure determination have confirmed that compound 2 was formed phase-pure (Fig. 8).

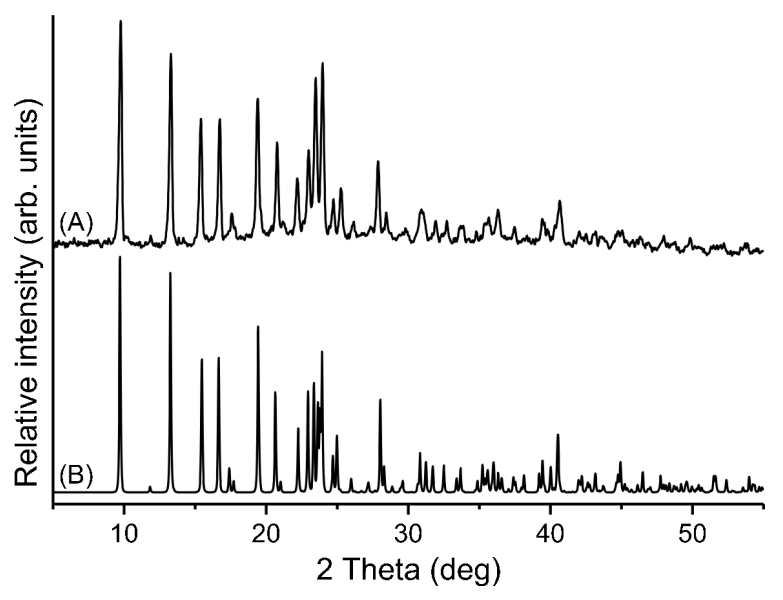

Fig. 8. Experimental powder pattern (A) together with a powder pattern calculated from single-crystal data of compound $2(\mathrm{~B})$.

\section{Crystal structure of the ligand-rich precursor 2}

The $1: 2: 2$ compound [Co(NCS) $)_{2}$ (3-methylpyridine $)_{2}\left(\mathrm{H}_{2} \mathrm{O}\right)_{2}$ ] crystallizes in the centrosymmetric monoclinic space group $P 2_{1} / c$ with two formula units in the unit cell and is isotypic to its $\mathrm{Ni}(\mathrm{II})$ compound reported recently [39]. The cobalt(II) cations are located on a center of inversion and coordinated by four $\mathrm{N}$ atoms of two terminally $\mathrm{N}$-bonded thiocyanato anions and two 3-methylpyridine coligands, as well as by two $\mathrm{O}$ atoms of two water molecules, all in mutually trans orientation, within a slightly distorted octahedral coordination geometry (Fig. 9). The $\mathrm{Co}^{\mathrm{II}}-\mathrm{N}$ distances are between 2.0831(19) and 2.1723(17) $\AA$, while the angles around the cobalt(II) cations range from 88.06(7) to $180^{\circ}$ (Table 3 ).

These discrete complexes are further linked via $\mathrm{S} \cdots \mathrm{H}-\mathrm{O}$ hydrogen bonds into layers, which are located parallel to the crystallographic $b c$ plane and are stacked along the crystallographic $a$ axis. The $\mathrm{S} \cdots \mathrm{H}-$ O distances range from 2.3987(5) to $2.4525(6) \AA$, and the angles lie between 153.633(1) and 177.701(1) . The $\mathrm{Co}^{\mathrm{II}}-\mathrm{Co}^{\mathrm{II}}$ intralayer separations range between 7.6338(4) and 7.8271(4) $\AA$, whereas the $\mathrm{Co}^{\mathrm{II}}-$ $\mathrm{Co}^{\mathrm{II}}$ interlayer distances range between 9.1928(6) and $12.8900(9) \AA$.

Table 3. Selected bond lengths $(\AA)$ and angles (deg) for 2. Symmetry code: A: $-x+1,-y+1,-z+1$.

\begin{tabular}{llll}
\hline $\mathrm{Co}(1)-\mathrm{N}(1)$ & $2.0831(19)$ & $\mathrm{N}(1)-\mathrm{Co}(1)-\mathrm{O}(1)$ & $91.94(7)$ \\
$\mathrm{Co}(1)-\mathrm{O}(1)$ & $2.1053(15)$ & $\mathrm{N}(1)-\mathrm{Co}(1)-\mathrm{O}(1 \mathrm{~A})$ & $88.06(7)$ \\
$\mathrm{Co}(1)-\mathrm{N}(11)$ & $2.1723(17)$ & $\mathrm{N}(1)-\mathrm{Co}(1)-\mathrm{N}(11)$ & $89.39(7)$ \\
$\mathrm{N}(1)-\mathrm{Co}(1)-\mathrm{N}(1 \mathrm{~A})$ & 180 & $\mathrm{~N}(1)-\mathrm{Co}(1)-\mathrm{N}(11 \mathrm{~A})$ & $90.61(7)$ \\
\hline
\end{tabular}

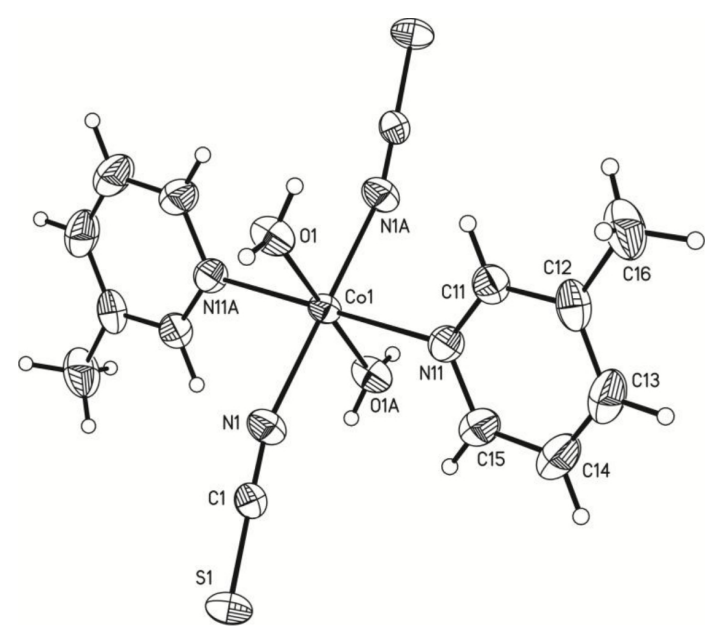

Fig. 9. Crystal structure of compound 2 with labeling and displacement ellipsoids drawn at the $50 \%$ probability level. Symmetry transformation used to generate equivalent atoms: A: $-x+1,-y+1,-z+1$.

\section{Thermoanalytical investigations of $\mathbf{2}$}

On heating compound $\mathbf{2}$ in a thermobalance to $400{ }^{\circ} \mathrm{C}$, a stepwise decomposition is observed. The 


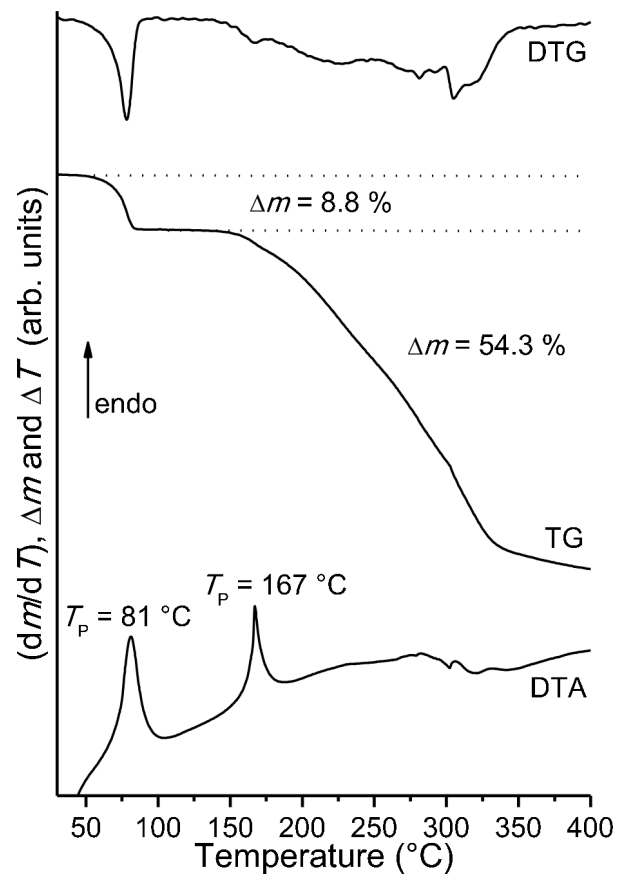

Fig. 10. DTG, TG and DTA curves for compound 2. Heating rate $=4{ }^{\circ} \mathrm{C} \mathrm{min}-1$; given are the mass changes $(\%)$ and the peak temperatures $T_{\mathrm{P}}\left({ }^{\circ} \mathrm{C}\right)$.

DTG curve for 2 shows that the first mass step is very well resolved and accompanied by an endothermic event in the DTA curve at $81{ }^{\circ} \mathrm{C}$ (Fig. 10). The mass loss in the second step is also accompanied by an endothermic event in the DTA curve at $167{ }^{\circ} \mathrm{C}$, but this step is not well resolved (Fig. 10). The experimental mass loss in the first step of $8.8 \%$ is in perfect agreement with that calculated for the removal of two molecules of water $\left(\Delta m_{\text {calcd. }}=-8.8 \%\right)$ (Fig. 10). Thus, it can be assumed that in the first step a liganddeficient $1: 2$ compound of composition $\left[\mathrm{Co}(\mathrm{NCS})_{2}(3-\right.$ methylpyridine $)_{2}$ ] is formed, and that in the second mass step the remaining 3-methylpyridine coligands are removed, and residual $\mathrm{Co}(\mathrm{NCS})_{2}$ decomposes on further heating (Fig. 10).

In order to verify the nature of the intermediate formed, additional TG measurements were performed and stopped after the first mass step. Comparison of the experimental XRPD pattern of the residue formed in thermal decomposition of $\mathbf{2}$ with that calculated for compound $\mathbf{3}$ clearly proves that $\mathbf{3}$ was formed phasepure after the first mass step (Fig. 11).

To investigate the reversibility of the dehydration of compound $\mathbf{2}$, the ligand-deficient intermediate $\mathbf{3}$ was stored in a saturated water atmosphere in a desiccator.

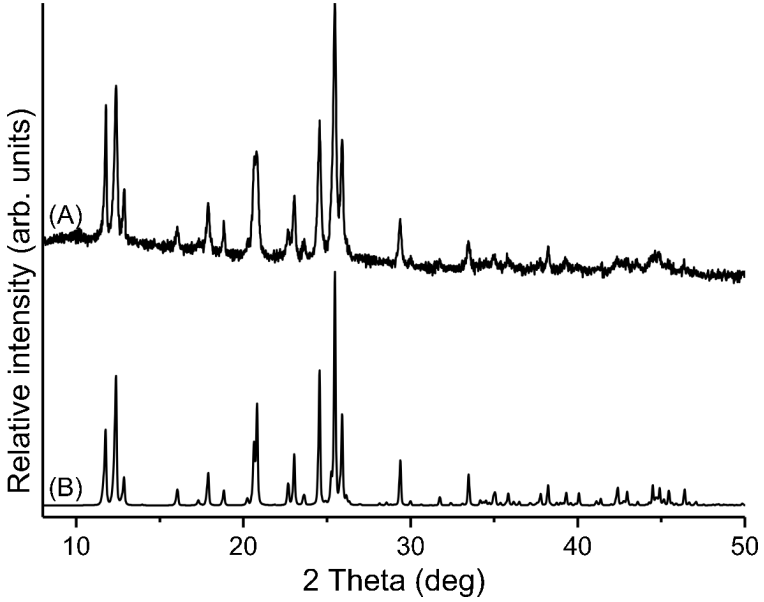

Fig. 11. Experimental powder pattern of the residue obtained in the thermal decomposition of $\mathbf{2}$ (A) together with a powder pattern calculated from single-crystal data of compound $\left[\mathrm{Co}(\mathrm{NCS})_{2}(3 \text {-picoline })_{2}\right](3)(\mathrm{B})$.

Even after several weeks no rehydration was observed. If compound $\mathbf{3}$ is stirred in water at r.t., rehydration starts immediately and is complete within one day. Dehydration of compound $\mathbf{2}$ can also be achieved if the ligand-rich hydrate $\mathbf{2}$ is stored under vacuum in a desiccator.

\section{Conclusion}

In this contribution we describe the results of investigations of new coordination compounds based on cobalt(II) thiocyanate and 3-methylpyridine as a neutral $\mathrm{N}$-donor coligand regarding their structures and thermal degradation behavior. These investigations were performed in order to check if 1D compounds can be obtained on thermal decomposition as it was recently reported for similar compounds with pyridine as the coligand $[26,27]$. Several experiments using different molar ratios of the starting materials resulted in the formation of the new ligand-rich discrete complexes $\left[\mathrm{Co}(\mathrm{NCS})_{2}(3 \text {-methylpyridine })_{4}\right]$ (1) and $\left[\mathrm{Co}(\mathrm{NCS})_{2}(3 \text {-methylpyridine })_{2}\left(\mathrm{H}_{2} \mathrm{O}\right)_{2}\right]$ (2). On heating compounds 1 and 2, a stepwise decomposition is observed leading in the first mass step to the ligand-deficient compound $\left[\mathrm{Co}(\mathrm{NCS})_{2}\right.$ (3-methylpyridine $)_{2}$ ] (3). In contrast to earlier investigations on cobalt(II) thio- and selenocyanate with pyridine as the neutral coligand, the octahedral coordination geometry is not retained in the ligand-deficient intermediate $\mathbf{3}$, and the thiocyanato anions are still terminally $\mathrm{N}$-bonded. This behavior is really surprising for sev- 
eral reasons. First of all, when investigating the corresponding compounds with 3-chloro- and 3-bromopyridine as coligands, we always observed the formation of compounds featuring chains with octahedral metal coordination as products of the thermal decomposition. Secondly, when investigating several other ligand-rich precursors based on diamagnetic cadmium thio- and selenocyanate with different coligands, we always found a similar thermal behavior. Moreover, in most cases the cadmium thio- and selenocyanato ligand-rich precursors as well as their ligand-deficient intermediates are isotypic to their paramagnetic counterparts. In this context it should be mentioned that the structure of the known $1: 2$ compound of cadmium thiocyanate and 3-methylpyridine as a coligand consists of chains with bridging thiocyanato anions. Therefore, we really have no idea why a discrete tetrahedral complex was always obtained in the present study. However, it must be pointed out that with pyridine derivatives that are substituted in 2-position we always obtained discrete tetrahedral complexes which presumably can be traced back to the steric demand of the substituents directly neighboring the coordinating $\mathrm{N}$ atom, but this argument is not valid for 3-methylpyridine. Therefore, it might be that electronic effects must be taken into account because, as mentioned above, with 3-chloro and 3-bromopyridine 1D structures can be obtained. In this context the question arises, if this is a general phenomenon for methylsubstituted pyridine derivatives, or if a different reactivity is observed if e.g. 4-methylpyridine is used as the coligand. This will be the subject of future investigations.

\section{Experimental Section}

\section{Materials}

All chemicals of reagent grade were commercially available and used without further purification.

\section{Powder X-ray diffraction}

The experiments were performed using 1) a Stoe Transmission Powder Diffraction System (STADI P) with $\mathrm{Cu} K_{\alpha 1}$ radiation $(\lambda=154.0598 \mathrm{pm})$ that is equipped with a linear position-sensitive detector $\left(\delta-2 \theta=6.5-7^{\circ}\right.$ simultaneous; scan range overall $=2-130^{\circ}$ ) from Stoe \& CIE and an image plate detector (scan range overall $=0-127^{\circ}$ ) and 2) a PANalytical X'Pert Pro MPD Reflection Powder Diffraction System with $\mathrm{Cu} K_{\alpha 1}$ radiation $(\lambda=154.0598 \mathrm{pm})$ equipped with a PIXcel semiconductor detector from PANalytical.

\section{Differential thermal analysis and thermogravimetry}

The DTA-TG measurements were performed in nitrogen atmosphere (purity: 5.0) in $\mathrm{Al}_{2} \mathrm{O}_{3}$ crucibles using a STA409CD thermobalance from Netzsch. All measurements were performed with a flow rate of $75 \mathrm{~mL} \mathrm{~min}^{-1}$ and were corrected for buoyancy and current effects. The instrument was calibrated using standard reference materials.

\section{Elemental analysis}

CHNS analysis was performed using an EURO EA elemental analyzer, fabricated by Euro Vector Instruments and Software.

\section{Spectroscopy}

IR spectra were recorded on an Alpha IR spectrometer from Bruker equipped with a Platinum ATR QuickSnap ${ }^{\text {TM }}$ sampling module between $4000-375 \mathrm{~cm}^{-1}$.

\section{Synthesis of $\left[\mathrm{Co}(\mathrm{NCS})_{2}(3 \text {-methylpyridine })_{4}\right]$ (1)}

$174.8 \mathrm{mg} \mathrm{Co}(\mathrm{NCS})_{2}(1.00 \mathrm{mmol})$ and $0.58 \mathrm{~mL} 3$-methylpyridine $(6.00 \mathrm{mmol})$ were stirred in $1.5 \mathrm{~mL}$ of water for $3 \mathrm{~d}$. Yield: $85 \%$. Single crystals suitable for X-ray diffraction were prepared by the reaction of $43.8 \mathrm{mg} \mathrm{Co}(\mathrm{NCS})_{2}$ $(0.25 \mathrm{mmol})$ and $0.24 \mathrm{~mL} \mathrm{3-methylpyridine}(2.50 \mathrm{mmol})$ in $1.0 \mathrm{~mL}$ of water at $130{ }^{\circ} \mathrm{C}$ in a closed glass tube. After $3 \mathrm{~d}$, light-pink well-shaped single crystals were obtained. $-\mathrm{C}_{26} \mathrm{H}_{28} \mathrm{CoN}_{6} \mathrm{~S}_{2}$ (547.59): calcd. C 57.0, H 5.1, N 15.4, S 11.7; found C 56.7, H 5.1, N 15.4, S 11.7.

\section{Synthesis of $\left[\mathrm{Co}(\mathrm{NCS})_{2}(3-\text { methylpyridine })_{2}\left(\mathrm{H}_{2} \mathrm{O}\right)_{2}\right](2)$}

$1748.7 \mathrm{mg} \mathrm{Co}(\mathrm{NCS})_{2}(10.00 \mathrm{mmol})$ and $0.10 \mathrm{~mL} \mathrm{3-}$ methylpyridine $(1.00 \mathrm{mmol})$ were stirred in $3.0 \mathrm{~mL}$ of water for $3 \mathrm{~d}$. Yield: $68 \%$. Single crystals suitable for X-ray diffraction were prepared by the reaction of $96.6 \mathrm{mg} \mathrm{Co}(\mathrm{NCS})_{2}(0.50 \mathrm{mmol})$ and $24.7 \mu \mathrm{L} \mathrm{3-meth-}$ ylpyridine $(0.25 \mathrm{mmol})$ in $1.5 \mathrm{~mL}$ of water in a closed $3 \mathrm{~mL}$ snap cap vial. After $3 \mathrm{~d}$, orange well-shaped single crystals were obtained. $-\mathrm{C}_{14} \mathrm{H}_{18} \mathrm{CoN}_{4} \mathrm{O}_{2} \mathrm{~S}_{2}$ (397.37): calcd. C 42.3, H 4.6, N 14.1, S 16.1; found C 42.1, H 4.5, N 13.9, S 15.8 .

\section{Single-crystal structure analysis}

All investigations were performed with an imaging plate diffraction system (IPDS-2) with $\mathrm{Mo} K_{\alpha}$ radiation from Stoe $\&$ CIE. The structure solution was performed with Direct Methods using SHELXS-97 [40], and structure refinements were performed against $F^{2}$ using SHELXL-97 [40]. All nonhydrogen atoms were refined with anisotropic displacement 
Table 4. Selected crystal data and details on the structure determinations for $\mathbf{1}-\mathbf{3}$.

\begin{tabular}{|c|c|c|c|}
\hline Compound & $\mathbf{1}$ & 2 & 3 \\
\hline Formula & $\mathrm{C}_{26} \mathrm{H}_{28} \mathrm{CoN}_{6} \mathrm{~S}_{2}$ & $\mathrm{C}_{14} \mathrm{H}_{18} \mathrm{CoN}_{4} \mathrm{O}_{2} \mathrm{~S}_{2}$ & $\mathrm{C}_{14} \mathrm{H}_{14} \mathrm{CoN}_{4} \mathrm{~S}_{2}$ \\
\hline$M_{r}, \mathrm{~g} \mathrm{~mol}^{-1}$ & 547.59 & 397.37 & 361.34 \\
\hline Crystal system & orthorhombic & monoclinic & orthorhombic \\
\hline Space group & Pbcn & $P 2_{1} / c$ & Pnma \\
\hline$a, \AA$ & $17.4562(10)$ & $9.1928(6)$ & $8.1081(4)$ \\
\hline$b, \AA$ & $8.9635(5)$ & $13.1086(8)$ & $3.7354(5)$ \\
\hline$c, \AA$ & $17.279(7)$ & $7.8271(4)$ & $15.0179(5)$ \\
\hline$\beta, \operatorname{deg}$ & 90 & $98.142(7)$ & 90 \\
\hline$V, \AA^{3}$ & $2703.6(11)$ & $933.70(10)$ & $1672.51(12)$ \\
\hline$T, \mathrm{~K}$ & $220(2)$ & $220(2)$ & 293(2) \\
\hline$Z$ & 4 & 2 & 4 \\
\hline$D_{\text {calcd }}, \mathrm{g} \mathrm{cm}^{-3}$ & 1.35 & 1.41 & 1.44 \\
\hline$\mu, \mathrm{mm}^{-1}$ & 0.8 & 1.2 & 1.3 \\
\hline$\theta_{\max }, \operatorname{deg}$ & 27.00 & 27.00 & 27.54 \\
\hline Measured / unique refl. / $R_{\text {int }}$ & 12239 / 2882 / 0.0376 & $1948 / 1948 / 0.0336$ & 21904 / 1984 / 0.0353 \\
\hline Refl. $F_{0} \geq 4 \sigma\left(F_{0}\right)$ & 2208 & 1452 & 1809 \\
\hline Ref. parameters & 162 & 109 & 107 \\
\hline$R_{1}{ }^{\mathrm{a}}\left[F_{0} \geq 4 \sigma\left(F_{0}\right)\right]$ & 0.0344 & 0.0281 & 0.0482 \\
\hline$w R_{2}^{\mathrm{b}}$ (all data) & 0.0916 & 0.0635 & 0.1181 \\
\hline $\mathrm{GOF}^{\mathrm{c}}$ & 1.023 & 0.841 & 1.167 \\
\hline$\Delta \rho_{\max / \min }, \mathrm{e} \AA^{-3}$ & $0.60 /-0.30$ & $0.26 /-0.41$ & $0.50 /-0.40$ \\
\hline
\end{tabular}

${ }^{\mathrm{a}} R 1=\Sigma|| F_{\mathrm{o}}|-| F_{\mathrm{c}} \| / \Sigma\left|F_{\mathrm{o}}\right| ;{ }^{\mathrm{b}} w R 2=\left[\Sigma w\left({F_{\mathrm{o}}}^{2}-{F_{\mathrm{c}}}^{2}\right)^{2} / \Sigma w\left({F_{\mathrm{o}}}^{2}\right)^{2}\right]^{1 / 2}, w=\left[\sigma^{2}\left(F_{\mathrm{o}}{ }^{2}\right)+(\mathrm{A} P)^{2}+\mathrm{B} P\right]^{-1}$, where $P=\left(\mathrm{Max}\left(F_{\mathrm{o}}{ }^{2}, 0\right)+2 F_{\mathrm{c}}{ }^{2}\right) / 3$; ${ }^{\mathrm{c}} \mathrm{GoF}=\left[\Sigma w\left(F_{\mathrm{o}}^{2}-F_{\mathrm{c}}^{2}\right)^{2} /\left(n_{\mathrm{obs}}-n_{\mathrm{param}}\right)\right]^{1 / 2}$.

parameters. The hydrogen atoms were positioned with idealized geometry and were refined with fixed isotropic displacement parameters $\left[U_{\text {iso }}(\mathrm{H})=-1.2 U_{\mathrm{eq}}(\mathrm{C})\right]$ and $\left[U_{\text {iso }}(\mathrm{H})=\right.$ $\left.1.5 U_{\text {eq }}(\mathrm{O})\right]$ using a riding model. In $\mathbf{1}$ the methyl $\mathrm{H}$ atoms at $\mathrm{C} 16$ are disordered and were refined with two different orientations each of them rotated by $60^{\circ}$. The crystal of compound 2 was non-merohedrally twinned. Both individuals were indexed separately, and the twin law was calculated. Afterwards the refinement was performed using the HKLF5 option in SHELXL. Details of the structure determination are given in Table 4.

CCDC 832183 (1), 832181 (2), and 832182 (3) contain the supplementary crystallographic data for this paper. These data can be obtained free of charge from The Cambridge Crystallographic Data Centre via www.ccdc.cam.ac.uk/ data_request/cif.
Elemental analysis of the residue $\mathbf{3}$ obtained in the thermal decomposition

The samples were isolated after the first heating step (see thermoanalytical investigations) of compounds $\mathbf{1}$ and 2. Analysis of the ligand-deficient compound 3: $\mathrm{C}_{14} \mathrm{H}_{14} \mathrm{CoN}_{4} \mathrm{~S}_{2}$ (361.36): calcd. C 46.5, H 3.9, N 15.5, S 17.7; found C 46.2, H 3.9, N 15.1, S 17.6.

\section{Acknowledgements}

This project was supported by the Deutsche Forschungsgemeinschaft (Project No. NA 720/3-1) and the State of Schleswig-Holstein. We thank Professor Dr. W. Bensch for access to his experimental facility. Special thanks go to I. Jeß for the single-crystal measurements.
[1] L. Bogani, A. Vindigni, R. Sessoli, D. Gatteschi, J. Mater. Chem. 2008, 18, 4750-4758.

[2] C. Coulon, R. Clérac, L. Lecren, W. Wernsdorfer, H. Miyasaka, Phys. Rev. B 2004, 69, 132408.

[3] C. Coulon, H. Miyasaka, R. Clérac in Single-Molecule Magnets and Related Phenomena, Vol. 122 (Ed.: R. Winpenny), Springer Berlin, Heidelberg, 2006, pp. $163-206$.

[4] H. Miyasaka, R. Clérac, Bull. Chem. Soc. Jpn. 2005, $78,1725-1748$.
[5] H. L. Sun, Z. M. Wang, S. Gao, Coord. Chem. Rev. 2010, 254, $1081-1100$.

[6] M. N. Leuenberger, D. Loss, Nature 2001, 410, 789 793.

[7] R. Mas-Ballesté, J. Gómez-Herrero, F. Zamora, Chem. Soc. Rev. 2010, 39, 4220 - 4233.

[8] R. Georges, J. J. Borrás-Almenar, E. Coronado, J. Curély, M. Drillon in Magnetism: Molecules to Materials (Eds.: J. S. Miller, M. Drillon), WILEY-VCH, Weinheim, 2001, pp. 1-43. 
[9] A. Caneschi, D. Gatteschi, N. Lalioti, C. Sangregorio, R. Sessoli, G. Venturi, A. Vindigni, A. Rettori, M. G. Pini, M. A. Novak, Angew. Chem. 2001, 113, $1810-$ 1813; Angew. Chem. Int. Ed. 2001, 40, 1760-1763.

[10] R. J. Glauber, J. Math. Phys. 1963, 4, 294-307.

[11] R. Clérac, H. Miyasaka, M. Yamashita, C. Coulon, J. Am. Chem. Soc. 2002, 124, 12837 - 12844.

[12] T.-F. Liu, D. Fu, S. Gao, Y.-Z. Zhang, H.-L. Sun, G. Su, Y.-J. Liu, J. Am. Chem. Soc. 2003, 125, 13976-13977.

[13] Z.-M. Sun, A. V. Prosvirin, H.-H. Zhao, J.-G. Mao, K. R. Dunbar, J. Appl. Phys. 2005, 97, 10B305-303.

[14] Z. He, Z.-M. Wang, S. Gao, C.-H. Yan, Inorg. Chem. 2006, 45, 6694-6705.

[15] N. Ishii, Y. Okamura, S. Chiba, T. Nogami, T. Ishida, J. Am. Chem. Soc. 2007, 130, 24-25.

[16] E. Coronado, J. R. Galán-Mascarós, C. Martí-Gastaldo, J. Am. Chem. Soc. 2008, 130, $14987-14989$.

[17] H.-L. Sun, Z.-M. Wang, S. Gao, Chem.-Eur. J. 2009, $15,1757-1764$.

[18] R. Gheorghe, A. M. Madalan, J.-P. Costes, W. Wernsdorfer, M. Andruh, Dalton Trans. 2010, 39, $4734-$ 4736.

[19] Z.-X. Li, Y.-F. Zeng, H. Ma, X.-H. Bu, Chem. Commun. 2010, 46, 8540-8542.

[20] E. Pardo, C. Train, R. Lescouezec, Y. Journaux, J. Pasan, C. Ruiz-Perez, F. S. Delgado, R. Ruiz-Garcia, F. Lloret, C. Paulsen, Chem. Commun. 2010, 46, $2322-$ 2324.

[21] C.-I. Yang, Y.-J. Tsai, S.-P. Hung, H.-L. Tsai, M. Nakano, Chem. Commun. 2010, 46, 5716-5718.

[22] D. Zhang, L.F. Zhang, Y. Chen, H. Wang, Z. H. Ni, W. Wernsdorfer, J. Jiang, Chem. Commun. 2010, 46, $3550-3552$.

[23] J. Ferrando-Soria, E. Pardo, R. Ruiz-García, J. Cano, F. Lloret, M. Julve, Y. Journaux, J. Pasán, C. RuizPérez, Chem. Eur. J. 2011, 17, 2176-2188.

[24] Q.-X. Jia, H. Tian, J.-Y. Zhang, E.-Q. Gao, Chem. Eur. J. 2011, 17, 1040-1051.
[25] C.-I. Yang, P.-H. Chuang, K.-L. Lu, Chem. Commun. 2011, 47, $4445-4447$.

[26] J. Boeckmann, C. Näther, Dalton Trans. 2010, 39, $11019-11026$.

[27] J. Boeckmann, C. Näther, Chem. Commun. 2011, 47, $7104-7106$.

[28] M. Wriedt, C. Näther, Dalton Trans. 2009, $10192-$ 10198.

[29] M. Wriedt, C. Näther, Chem. Commun. 2010, 46, $4707-4709$.

[30] M. Wriedt, S. Sellmer, C. Näther, Inorg. Chem. 2009, 48, 6896-6903.

[31] M. Wriedt, S. Sellmer, C. Näther, Dalton Trans. 2009, $7975-7984$.

[32] S. Wöhlert, J. Boeckmann, M. Wriedt, C. Näther, Angew. Chem. 2011, 123, 7053 -7056; Angew. Chem. Int. Ed. 2011, 50, 6920-6923.

[33] M. Taniguchi, Y. Sugita, A. Ouchi, Bull. Chem. Soc. Jpn. 1987, 60, $1321-1326$.

[34] J. Boeckmann, I. Jeß, T. Reinert, C. Näther, Eur. J. Inorg. Chem. 2011, submitted.

[35] G. Bhosekar, J. Boeckmann, I. Jeß, C. Näther, Z. Anorg. Allg. Chem. 2010, 636, $2595-2601$.

[36] J. Boeckmann, T. Reinert, I. Jeß, C. Näther, Z. Anorg. Allg. Chem. 2011, 637, $1137-1144$.

[37] J. Boeckmann, T. Reinert, C. Näther, Z. Anorg. Allg. Chem. 2011, 637, 940-946.

[38] R. A. Bailey, S. L. Kozak, T.W. Michelsen, W. N. Mills, Coord. Chem. Rev 1971, 6, 407-445.

[39] X.-N. Tan, Y.-X. Che, J.-M. Zheng, Chin. J. Struct. Chem. 2006, 25, 358-362.

[40] G. M. Sheldrick, SHELXs/L-97, Programs for Crystal Structure Determination, University of Göttingen, Göttingen (Germany) 1997. See also: G. M. Sheldrick, Acta Crystallogr. 1990, A46, 467-473; ibid. 2008, A64, 112 - 122 . 